\title{
Surgeon General's Armed Forces Feeding Project: body composition and dietary intake of Royal Navy recruits
}

\author{
A. Dziubak ${ }^{1}$, C. House ${ }^{1}$, R. Taylor ${ }^{1}$, R. Cobley ${ }^{1}$, E. Minnock $^{2}$, P. Zioupos ${ }^{2}$, T. Davey ${ }^{1}$, \\ A. J. Allsopp ${ }^{1}$ and J. L. Fallowfield ${ }^{1}$ \\ ${ }^{1}$ Institute of Naval Medicine, Crescent Road, Alverstoke, Gosport, Hants PO12 2DL and \\ ${ }^{2}$ Biomechanics Laboratories, DASSR, Cranfield University, DACMT, Shrivenham SN6 8LA, UK
}

Royal Navy (RN) recruits undertake the first phase of their training at HMS Raleigh, Torpoint, UK. This 9-week course is designed to train and educate recruits of the RN Ethos, ultimately preparing personnel to be operationally ready. The aim of this study was to evaluate the nutritional and physiological experiences of RN recruits undertaking the Phase-1 training syllabus at HMS Raleigh.

RN recruits commencing training at HMS Raleigh were given an initial study brief, after which 247 recruits (218 male; 29 female) from five recruit entries consented to participate in the study. Body mass, height and anthropometric measurements (skinfolds and girths) were taken at the start and end of training. Self-reported nutritional intake prior to commencing Phase-1 training was assessed using a validated Food Frequency Questionnaire ${ }^{(1)}$.

Body mass, body girths and estimated percentage body fat (\%body fat) decreased in male recruits during Phase-1 training $(P<0.05)$. Body mass and \%body fat remained constant in female recruits, but thigh girth, thigh and calf skinfolds increased and bicep, supraspinale and iliac crest skinfolds decreased $(P<0.05)$. A male recruit was less likely to complete Phase- 1 training in the nine weeks if they had a \%body fat of less than $10 \%$ or greater than $17.9 \%$ ( $R R=0.7$ and 0.8 , respectively). A female recruit was less likely to complete Phase- 1 training in the nine weeks if they had a \%body fat of more than or equal to $30 \%(\mathrm{RR}=0.5)$.

Relative to the World Health Organization's Body Mass Index classifications ${ }^{(2)}$, at the start of training $29 \%$ of male recruits and $38 \%$ of female recruits were overweight, and $5 \%$ of male recruits were obese. This is higher than previously reported for recruits starting Phase-1 RN training ${ }^{(3)}$.

The total energy and macronutrient (as percentage of total energy) intakes of recruits prior to commencing Phase-1 training are shown in the table below.

\begin{tabular}{|c|c|c|c|c|c|c|c|c|c|c|c|}
\hline & \multirow[b]{2}{*}{$n$} & \multicolumn{2}{|c|}{ Energy (kcal) } & \multicolumn{2}{|c|}{$\% \mathrm{CHO}$} & \multicolumn{2}{|c|}{$\%$ Fat } & \multicolumn{2}{|c|}{$\%$ Saturated Fat } & \multicolumn{2}{|c|}{$\%$ Protein } \\
\hline & & Mean & SD & Mean & SD & Mean & SD & Mean & SD & Mean & SD \\
\hline$m$ & 185 & 2578 & 851 & 42 & 5 & 35 & 4 & 15 & 3 & 17 & 3 \\
\hline$f$ & 23 & 2388 & 793 & 44 & 6 & 37 & 4 & 15 & 3 & 17 & 3 \\
\hline
\end{tabular}

The proportion of the total energy intake derived from fat (especially saturated fats) and carbohydrates was sub-optimal for regular physical training. ${ }^{(4)}$

These data indicate that more effective nutritional education needs to be implemented at HMS Raleigh, where the aim should be to promote healthier diets and improve the physical status of all RN Phase-1 recruits.

The authors would like to thank colleagues at HMS Raleigh, Torpoint, UK, for their support and assistance.

1. Leiper R, Fallowfield JL, Delaney S, Whittamore D, Dziubak A \& Lanham-New SA (2009) Institute of Naval Medicine Report No.: 2009.017.

2. World Health Organization (2000) Obesity: preventing and managing the global epidemic. Report of a WHO Consultation. WHO Technical Report Series. Report No.: 894(3), i-253.

3. Allsopp AJ, Scarpello EG, Andrews S \& Pethybridge RJ (2003) J Roy Nav Med Serv 89(1), 11-18.

4. Committee on Medical Aspects of Food Policy (1991) Report on health and social subjects. No. 41. Dietary reference values for food energy and nutrients for the United Kingdom. London: HMSO. 